\title{
PENGARUH BAP TERHADAP PEMBENTUKAN DAN PEMBESARAN UMBI MIKRO KENTANG KULTIVAR GRANOLA
}

(The Effect of BAP Plant Regulator to the formation and the development of Potato's Micro Tuber)

\author{
Danner Sagala ${ }^{1}$, Herman Wafom Tubur ${ }^{2}$, Uma Fatkhul Jannah, Chea Sinath ${ }^{3}$ \\ ${ }^{1}$ Fakultas Pertanian Universitas Prof. Dr. Hazairin, SH, Bengkulu \\ ${ }^{2}$ Fakultas Pertanian Universitas Negeri Papua, Papua \\ ${ }^{3}$ Prek Leap High School, Cambodia
}

\begin{abstract}
The experiment was aimed to know the effect of BAP Plant Regulator to the formation and the development of Potato's Micro Tuber. The treatment were $0 ; 2,5 ; 5 ; 7,5 \mathrm{mg} / \mathrm{L} \mathrm{BAP}$. The growing media was Murashige and Skoog (MS0). The result showed that BAP did not significantly affected the number, diameter, wet and dry weight of the tuber. However, the highest of number, diameter, wet and dry weight was found at the 7,5 mg/L BAP. The fastest formation of tuber was yielded in $5 \mathrm{mg} / \mathrm{L} \mathrm{BAP}$.
\end{abstract}

Key words: BAP plant regulator, Potato, Tuber, Murashige and Skoog

\section{PENDAHULUAN}

Kentang adalah salah satu tanaman hortikultura yang ditanam oleh petani di dataran tinggi. Kentang juga merupakan salah satu tanaman pangan dunia dan berpotensi besar untuk menunjang program diversifikasi pangan di Indonesia. Salah satu varietas kentang yang banyak dibudidayakan di Indonesia adalah varietas granola. Menurut Sahat et al. (1998) budidaya kentang granola diperkirakan 85 - 90 \% dari seluruh luasan lahan kentang di Indonesia.

Kebutuhan akan kentang terus meningkat di Indonesia. Menurut Ashari (1995), kentang merupakan bahan dasar tepung, keripik dan untuk industri alkohol. Banyak makanan ringan yang berbahan baku kentang. Selain sebagai makanan ringan kemasan, kentang juga digunakan oleh restoran-restoran cepat saji sebagai makanan tambahan seperti KFC, CFC, M'Donald dan lain-lain. Namun produksi kentang Indonesia belum mampu memenuhi kebutuhan tersebut. Data Deptan (2008) menunjukkan bahwa terjadi peningkatan produksi mulai tahun 2001 (831.140 ton) hingga tahun 2006 (1.011.911 ton), meskipun produksi ini masih jauh dibandingkan produksi tahun 2000 (2.004.179 ton)
Menurut Wattimena et al., (2003) salah satu penghambat utama produksi kentang Indonesia adalah kurangnya bibit kentang yang bermutu seperti benih kentang, bibit umbi kentang, bibit umbi hasil in vitro dengan harga yang wajar. Wattimena (2000) menyatakan bahwa penggunaan umbi mikro sebagai salah satu propagul kentang memiliki beberapa keuntungan yaitu akan menghasilkan propagul yang bebas penyakit, menghasilkan tanaman yang seragam dan umur panen yang sama dengan propagul umbi biasa, kebutuhan umbi mikro hanya 4 $5 \mathrm{~kg}$ per ha dibandingkan dengan umbi biasa yang memerlukan $1-2$ ton per ha, mudah dalam penyimpanan dan transportasi serta mudah memenuhi persyaratan karantina untuk lalulintas propagul baik dalam negeri maupun luar negeri.

Propagul umbi mikro diperoleh dengan perbanyakan secara in vitro. Aplikasi teknik kultur in vitro melalui pembiakan mikro dapat menghasilkan bibit dalam jumlah banyak dalam waktu yang relatif singkat, tidak tergantung pada iklim dan musim serta biaya penyediaan bibit relatif lebih murah dibandingkan bibit impor.

Untuk perbanyakan secara in vitro dibutuhkan media tumbuh yang mengandung 
bahan organik, hara makro dan mikro, kompleks alami dan bahan-bahan lain yang mendukung pertumbuhan tanaman. Air kelapa merupakan bahan organik yang kaya akan zat-zat aktif untuk perkembangan embrio, diantaranya adalah sitokinin endogen.

Percobaan ini bertujuan untuk melihat pengaruh BAP terhadap pembentukan dan pembesaran umbi mikro kentang kultivar Granola.

\section{BAHAN DAN METODE}

Percobaan dilaksanakan pada bulan Maret - Juni 2009 di Laboratorium Kultur Jaringan dan Laboratorium RGCI (Research Group of Crop Improvement), Departemen Agronomi dan Hortikultura, Fakultas Pertanian, Institut Pertanian Bogor. Bahan yang digunakan antara lain stek mikro kentang buku tunggal yang berasal dari kultur jaringan kultivar Granola, media MS, Calcium Pantotenat (CaP), BAP, alar, air kelapa, gula dan bahan-bahan untuk mengukur total gula dan total pati. Alat yang digunakan yaitu $\mathrm{pH}$ meter, autoklaf, alat-alat tanam, ruang kultur dengan lampu infloresense, penggaris, jangka sorong, alatalat untuk mengukur total gula dan total pati.

Penelitian dilaksanakan dalam dua tahap percobaan, yaitu tahap pertunasan dan tahap pengumbian. Tahap Pertunasan bertujuan untuk mendapatkan bahan tanam pada media $\mathrm{MS}_{0}$. Stek kentang yang terdiri dari dua buku ditanam dalam media $\mathrm{MS}_{0}$ secara horizontal. Setiap botol ukuran selai ditanami lima stek. Pengumbian bertujuan untuk mengetahui pengaruh konsentrasi BAP terhadap pembentukan dan pengumbian kentang kultivar Granola.

Media pertunasan menggunakan media MS0 yang ditambahkan Calcium pantotenat $2 \mathrm{mg} / \mathrm{l}$. Larutan stok dalam jumlah tertentu diambil. Kemudian ditera menjadi satu liter. Gula ditambahkan sebanyak $40 \mathrm{~g} / \mathrm{l}$. larutan media diaduk merata menggunakan sterer. Derajat keasaman media dipertahankan 5.8 6. $\mathrm{KOH} 1 \mathrm{~N}$ digunakan untuk menurunkan $\mathrm{pH}$ dan $\mathrm{HCl} 1 \mathrm{~N}$ untuk menaikkan $\mathrm{pH}$. Sebagai pemadat media digunakan agar-agar
7 g/l. Media yang telah dicampur agar-agar dimasak sampai mendidih, kemudian dituangkan dalam botol yang telah diautoklaf. Volume media yang dituangkan kedalam botol kurang lebih $25 \mathrm{ml} /$ botol. Tutup yang digunakan adalah plastik tahan panas yang diikat dengan karet gelang. Botol yang telah diisi media disterilkan menggunakan autoklaf selama 30 menit pada suhu $121{ }^{\circ} \mathrm{C}$ dengan tekanan 17.1 psi. Media didiamkan selama empat hari untuk melihat kontaminasi. Media yang tidak terkontaminasi digunakan untuk menanam.

Media pengumbian yang digunakan adalah media MS0 yang ditambahkan alar 10 $\mathrm{mg} / \mathrm{l}$, air kelapa $150 \mathrm{ml} / \mathrm{l}$, gula $90 \mathrm{~g} / \mathrm{l}$ dan BAP sesuai perlakuan. Media dibiarkan tetap dalam bentuk cair tanpa ditambahkan agaragar. Jumlah media pengumbian yang ditambahkan $30 \mathrm{ml} /$ botol. Perlakuan BAP sebagai berikut :

$$
\begin{aligned}
& \text { P1 : BAP } 0 \mathrm{mg} / \mathrm{l} \text { (tanpa BAP) } \\
& \text { P2 : BAP } 2.5 \mathrm{mg} / \mathrm{l} \\
& \text { P3 : BAP } 5 \mathrm{mg} / \mathrm{l} \\
& \text { P4 : BAP } 7.5 \mathrm{mg} / \mathrm{l}
\end{aligned}
$$

Penanaman stek mikro kentang dilakukan di dalam laminar air flow kabinet. Stek dari induk dipotong-potong setiap dua buku dalam cawan petri. Setiap botol terdiri dari lima buku yang ditanam secara horizontal. Kultur diletakkan pada ruang dengan pencahayaan penuh menggunakan lampu infloresene.

Media pengumbian ditambahkan ketika umur tanaman satu bulan. Tanaman yang sehat (tidak terkontaminasi) dibawa ke laminar air flow cabinet. Media pengumbian yang berbentuk cair ditambahkan sebanyak $30 \mathrm{ml} /$ botol, kemudian botol ditutup kembali. Botol ditempatlan di ruang yang gelap untuk menginduksi pengumbian.

\section{HASIL DAN PEMBAHASAN Persentase Kontaminasi}

Kontaminasi pada kultur jaringan bisa disebabkan oleh jamur atau oleh bakteri. Kontaminasi yang terjadi pada percobaan persiapan kultur sebesar $50.7 \%$. Kontaminasi paling tinggi terjadi pada mingu pertama setelah penanaman. 
Kontaminasi menurun pada pengamatan berikutnya. Setelah penambahan media pengumbian, kontaminasi dihitung berdasarkan perlakuan. Pada minggu pertama, P1 mengalami kontaminasi sebanyak 45 \%, P2 53 \%, P3 26 \% dan P4 26 $\%$. Pengamatan pada minggu berikutnya kontaminasi tetap terjadi, namun presentasenya menurun. Beberapa penyebab kontaminasi antara lain media dan alat-alat yang digunakan tidak steril, kurangnya kehati-hatian pada saat penanaman atau penambahan media pengumbian, sehinga kontaminan dapat masuk ke dalam botol kultur. Pada akhir pangamatan, kontaminasi total yang terjadi pada P1 sebesar $75 \%$, P2 80 \%, P3dan P4 $46 \%$.

\section{Pertumbuhan Eksplan pra-perlakuan (persiapan kultur)}

Pada percobaan praktikum yang dilakukan, aplikasi perlakuan diberi pada minggu kelima. Beberapa peubah pertumbuhan tanaman yang diukur selama pra-perlakuan antara lain tinggi tanaman, jumlah daun, jumlah ruas, dan jumlah tunas. Hasil pengamatan dapat dilihat pada Tabel 1. Media yang digunakan selama praperlakuan adalah media $\mathrm{MS}_{0}$, tunas tertinggi adalah 8,9 cm dan terendah adalah 5,96 cm, jumlah daun terbanyak adalah 11,2 daun dan yang paling sedikit adalah 7,89 daun, jumlah ruas terbanyak adalah 9,80 ruas dan ruas yang paling sedikit adalah 6,33 ruas, sementara jumlah tunas terbanyak adalah 11,60 tunas dan yang paling sedikit adalah 7,17 tunas. Tanaman kentang dapat tumbuh baik pada media $\mathrm{MS}_{0}$ karena sudah mengalami penyesuaian habituasi.

Tinggi tanaman, jumlah daun, ruas dan tunas tertinggi diperoleh dari tanaman yang ditanam pada media yang disiapkan untuk perlakuan BAP 5 mg/l (P3).

Tabel 1. Hasil Pengamatan pra-perlakuan (persiapan kultur)

\begin{tabular}{|c|c|c|c|c|}
\hline Pengamatan ke- & 1 & 2 & 3 & 4 \\
\hline \multicolumn{5}{|c|}{ Tinggi Tanaman (cm) } \\
\hline $\mathrm{P} 1$ & 1.63a & $3.39 b$ & $5.11 b$ & 7.61ab \\
\hline P2 & $1.37 \mathrm{a}$ & $3.49 \mathrm{~b}$ & $4.74 b$ & $6.06 \mathrm{cb}$ \\
\hline P3 & $1.84 \mathrm{a}$ & $4.40 \mathrm{a}$ & 7.04a & $8.90 \mathrm{a}$ \\
\hline P4 & 1.49a & $3.20 \mathrm{~b}$ & $4.30 \mathrm{~b}$ & $5.96 c$ \\
\hline Respon & tn & $*$ & $*$ & $* *$ \\
\hline \multicolumn{5}{|l|}{ Jumlah Daun } \\
\hline P1 & $2.94 a$ & $4.44 b$ & $5.31 b$ & $7.89 \mathrm{~b}$ \\
\hline P2 & $2.92 \mathrm{a}$ & 4.58ab & 6.17ab & $8.42 b$ \\
\hline P3 & $3.20 \mathrm{a}$ & $5.80 \mathrm{a}$ & 7.00ab & $11.20 \mathrm{a}$ \\
\hline P4 & $3.29 a$ & $5.29 \mathrm{ab}$ & $7.57 \mathrm{a}$ & 8.86ab \\
\hline Respon & tn & $*$ & $*$ & $*$ \\
\hline \multicolumn{5}{|l|}{ Jumlah ruas } \\
\hline $\mathrm{P} 1$ & $2.08 \mathrm{a}$ & 3.19a & $5.14 \mathrm{a}$ & $6.61 b$ \\
\hline P2 & 1.83a & 3.67a & $5.25 a$ & 6.33b \\
\hline P3 & $2.20 \mathrm{a}$ & $4.40 \mathrm{a}$ & $6.40 \mathrm{a}$ & 9.80a \\
\hline P4 & $2.00 \mathrm{a}$ & $3.57 \mathrm{a}$ & $5.71 \mathrm{a}$ & $7.00 \mathrm{~b}$ \\
\hline Respon & tn & tn & tn & $* *$ \\
\hline \multicolumn{5}{|l|}{ Jumlah Tunas } \\
\hline $\mathrm{P} 1$ & 5.33ab & 7.17b & 7.17b & $7.50 \mathrm{~b}$ \\
\hline $\mathrm{P} 2$ & $5.17 \mathrm{~b}$ & $6.50 \mathrm{~b}$ & $6.83 b$ & $7.17 \mathrm{~b}$ \\
\hline P3 & $8.00 \mathrm{a}$ & $10.00 \mathrm{a}$ & $11.20 \mathrm{a}$ & $11.60 \mathrm{a}$ \\
\hline P4 & 5.43ab & $7.14 b$ & $7.71 b$ & $8.14 b$ \\
\hline Respon & $*$ & $*$ & $*$ & $*$ \\
\hline
\end{tabular}

Ket : huruf yang sama pada kolom yang sama tidak berbeda nyata dengan uji DMRT taraf $5 \%$ 


\section{Waktu Mulai Terbentuknya Umbi}

Umbi mulai terbentuk pada minggu kedua setelah aplikasi perlakuan BAP. Planlet yang tercepat menghasilkan umbi adalah planlet yang diberikan perlakuan BAP 5 mg/l (P3). Pada minggu ketiga, umbi mulai keluar pada planlet yang diberi tidak diberikan BAP (P1), kemudiaan pada minggu keempat pada planlet yang diberikan perlakuan BAP 2,5 mg/l (P2) dan 7,5 mg/l (P4) (Gambar 1).

Salisbury \& Ross (1995) menyatakan sitokinin berperan dalam memacu pembelahan sel dan pembentukan organ. Penelitian-penelitian yang telah dilakukan pada berbagai jenis tanaman menunjukkan pengaruh yang nyata pemberian BAP baik pengaruh tunggal maupun dikombinasikan dengan zpt lainnya terhadap pengumbian dengan konsentrasi terbaik yang berbedabeda pula pada masing-masing jenis tanaman (Fariquel et al., 2004; Santi, 2004; Belleti, et al., 2009). Namun pada percobaan yang dilakukan belum dapat disimpulkan secara tegas bahwa konsentrasi BAP terbaik dalam mempercepat terbentuknya umbi mikro kentang. Hal ini karena pada peubah praperlakuan yang diamati seperti tinggi tunas, jumlah daun, jumlah tunas dan jumlah ruas, planlet yang tumbuh pada media yang akan diplikasikan P3 memiliki pertumbuhan yang terbaik.

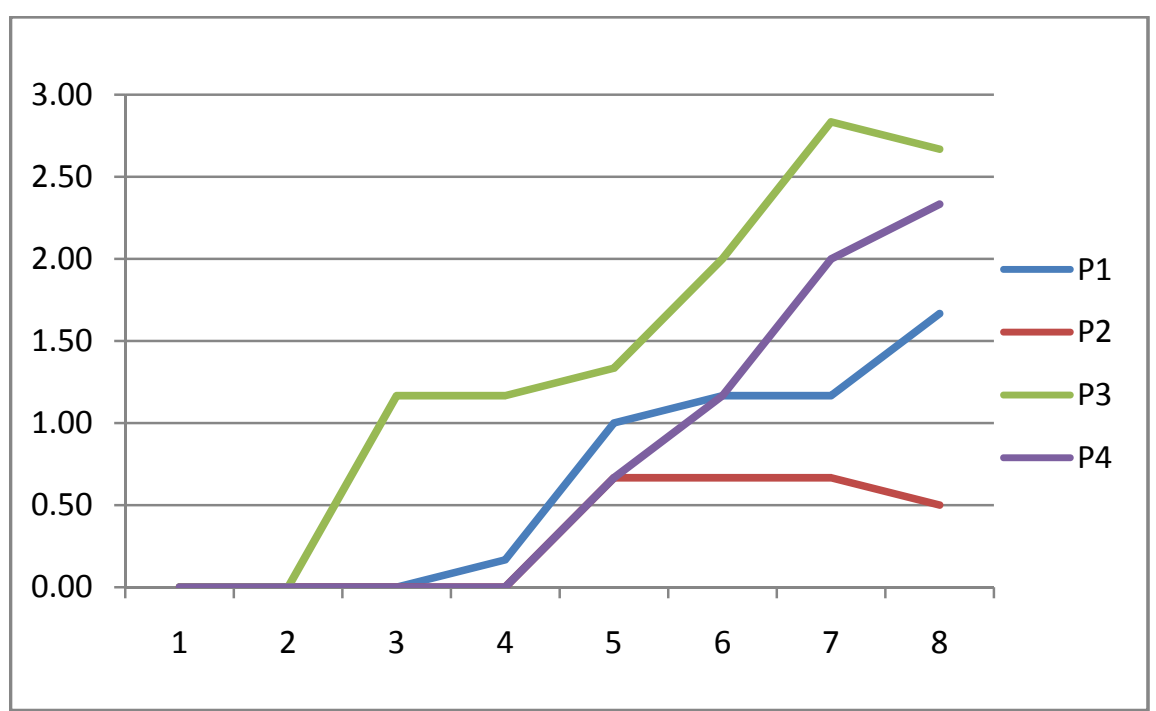

Gambar 1. Waktu Mulai Terbentuknya Umbi (Minggu). Perlakuan BAP 0 ppm (P1); 2,5 ppm (P2); 5 ppm (P3), dan 7,5 ppm (P4)

\section{Jumlah dan diameter umbi (mm)}

Uji DMRT jumlah dan diameter umbi pada taraf 5\% akibat perlakuan BAP 0 ppm; 2,5 ppm, 5 ppm dan 7,5 ppm tidak menunjukkan adanya perbedaan. Jumlah umbi tertinggi terdapat pada media yang diberi perlakuan konsentrasi BAP 5 ppm $(2,67)$ kemudian diikuti perlakuan BAP 7,5 ppm (2,33 ), dan perlakuan BAP 0 ppm $(1,67)$. Jumlah umbi terendah terdapat pada perlakuan BAP 2,5 ppm $(0,50)$. Diameter umbi tertinggi diperoleh pada perlakuan
BAP 5 ppm (4,33 mm) kemudian di susul perlakuan BAP 0 ppm $(3,86 \mathrm{~mm})$ dan perlakuan BAP 2,5 ppm (2,79 mm), dan diameter umbi terendah pada perlakuan BAP 7,5 ppm (2,69 mm) (Gambar 2). Konsentrasi BAP 5 ppm memberikan hasil tertinggi pada jumlah dan diameter umbi. Sitokinin memacu pembentukan umbi dengan jalan menghambat aktivitas hidrolisis pati dan sebaliknya merangsang aktivitas sintesis pati (Smith dan Palmer, 1970). 


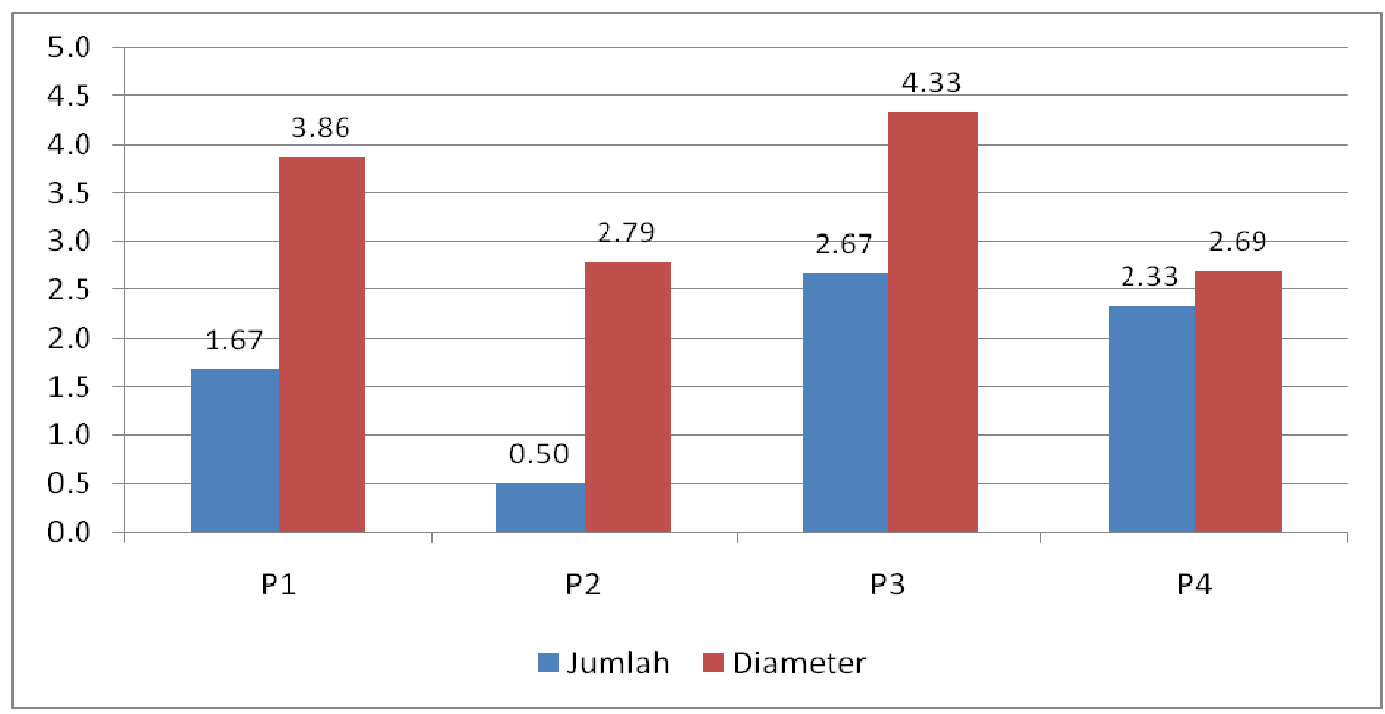

Gambar 2. Jumlah Dan Diameter Umbi Mikro Kentang Kultivar Granola yang terbentuk akibat perlakuan BAP 0 ppm (P1); 2,5 ppm (P2); 5 ppm (P3), dan 7,5 ppm (P4)

\section{Bobot basah dan bobot kering umbi}

Hasil uji DMRT pada taraf 5\%, menunjukan tidak ada perbedaan bobot basah dan bobot kering umbi mikro akibat perlakuan konsentrasi BAP. Pengaruh konsentrasi BAP terhadap bobot basah menunjukan bobot basah tertinggi diperoleh pada BAP 5 ppm $(0,123$ gr) kemudian diikuti perlakuan BAP 0 ppm (0,068 gr), dan BAP
7,5 ppm (0,031). Bobot umbi terendah terdapat pada perlakuan BAP 2,5 ppm (0,028 gr). Hasil bobot kering tertinggi diperoleh pada perlakuan 5 ppm (0,019 gr) kemudian diikuti dengan perlakuan BAP 0 ppm $(0,011)$ dan perlakuan BAP 2,5 ppm (0,008 gr). Bobot kering terendah diperoleh pada perlakuan BAP 7,5 ppm (0,007 gr) (Gambar $3)$.

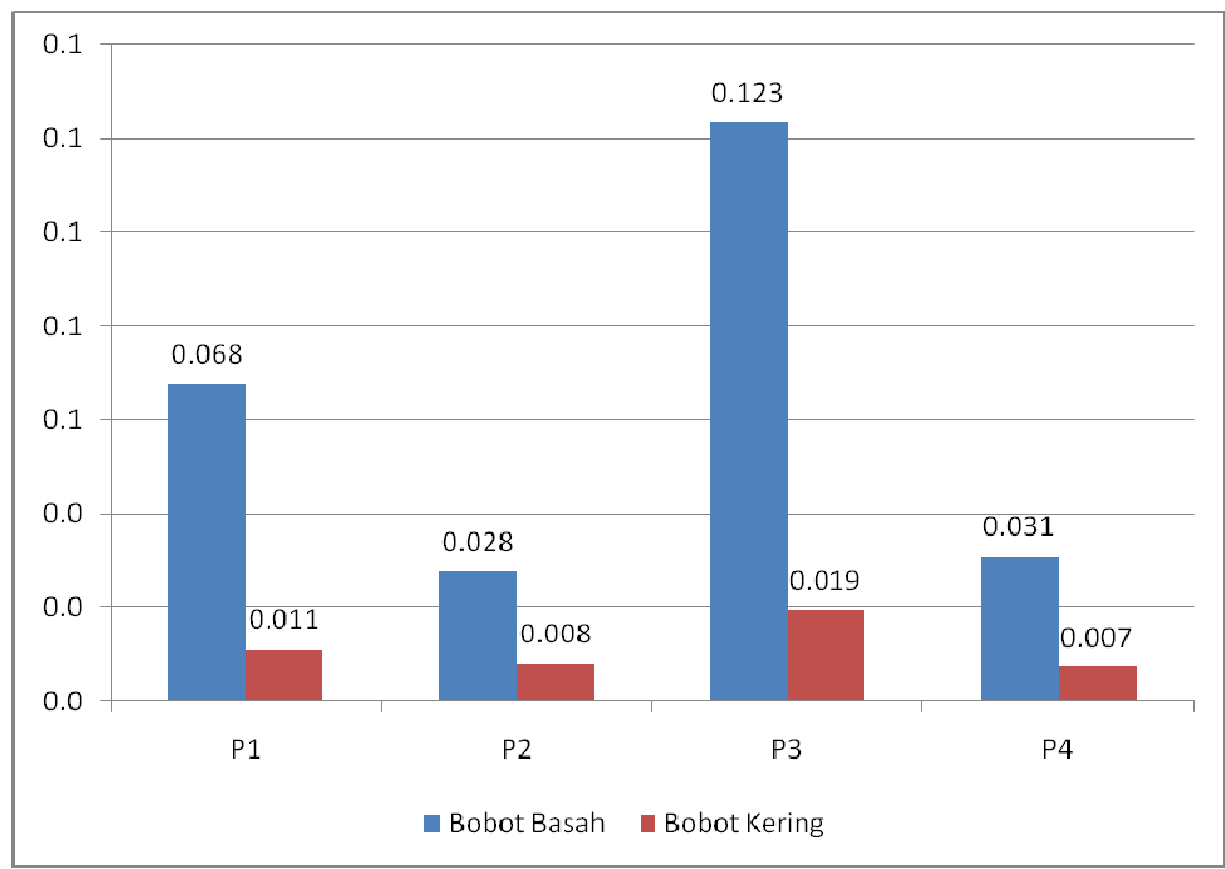

Gambar 3. Bobot Basah dan Bobot Kering Umbi Mikro Kentang Kultivar Granola akibat perlakuan BAP 0 ppm (P1); 2,5 ppm (P2); 5 ppm (P3), dan 7,5 ppm (P4). 
Tingginya bobot basah umbi berpengaruh pada peningkatan bobot kering. Peningkatan bobot basah dan bobot kering merupakan hasil dari aktivitas pembesaran sel dalam hal ini BAP berperan dalam memacu pembesaran sel, yang menyebabkan peningkatan bobot basah (Salisburry and Ross,1995). Dalam percobaan ini konsentrasi BAP 5 ppm memberikan hasil bobot basah dan bobot kering umbi tertinggi dibandingkan taraf konsentrasi BAP 2,5 ppm dan 7,5 ppm.

\section{Gula dan pati total}

Gambar 4 menunjukkan bahwa perlakuan BAP 7,5 mg/l memberi pati yang paling tinggi (0,806 g/g sampel), diikuti oleh pelakuan kontrol (0.284 g/g sampel), kemudian pelakuan BAP 5mg/l (0,262 g/g sampel). Pelakuan BAP 2,5 mg/l tidak mempunyai cukup sampel untuk analisa pati dan gula. Pelakuan BAP 7,5 mg/l juga menghasilkan gula yang paling tinggi $(0,076$ g/g sampel), diikuti oleh pelakuan BAP 5 mg/l (0,063 g/g sampel), kamudian pelakuan kontrol menghasilkan hanya $0,040 \mathrm{~g} / \mathrm{g}$ sampel.

Menurut Moorby and Milthorpe. (1975), asimilat karbon ditranslokasi ke umbi dalam bentuk sukrosa, kemudian digunakan sebagai bahan dalam sintesis pati. Smith dan Palmer, (1970) menunjukkan bahwa sitokinin memacu pembentukan umbi dengan jalan menghambat aktivitas hidrolisis pati dan sebaliknya merangsang aktivitas sintesis pati. Munin et al. (2008) juga menemukan bahwa penggunaan kinetin dan BAP secara kultur in vitro meningkatkan bahan kering selama tahap aklimatizasi. Namun, dalam percobaan ini pati tidak konsisten dengan konsentrasi BAP, sedangkan BAP menujukkan konsistensi dengan kandungan gula. Hal ini mungkin akibat dari persiapan planlet yang tidak homogen sebelum aplikasi BAP.

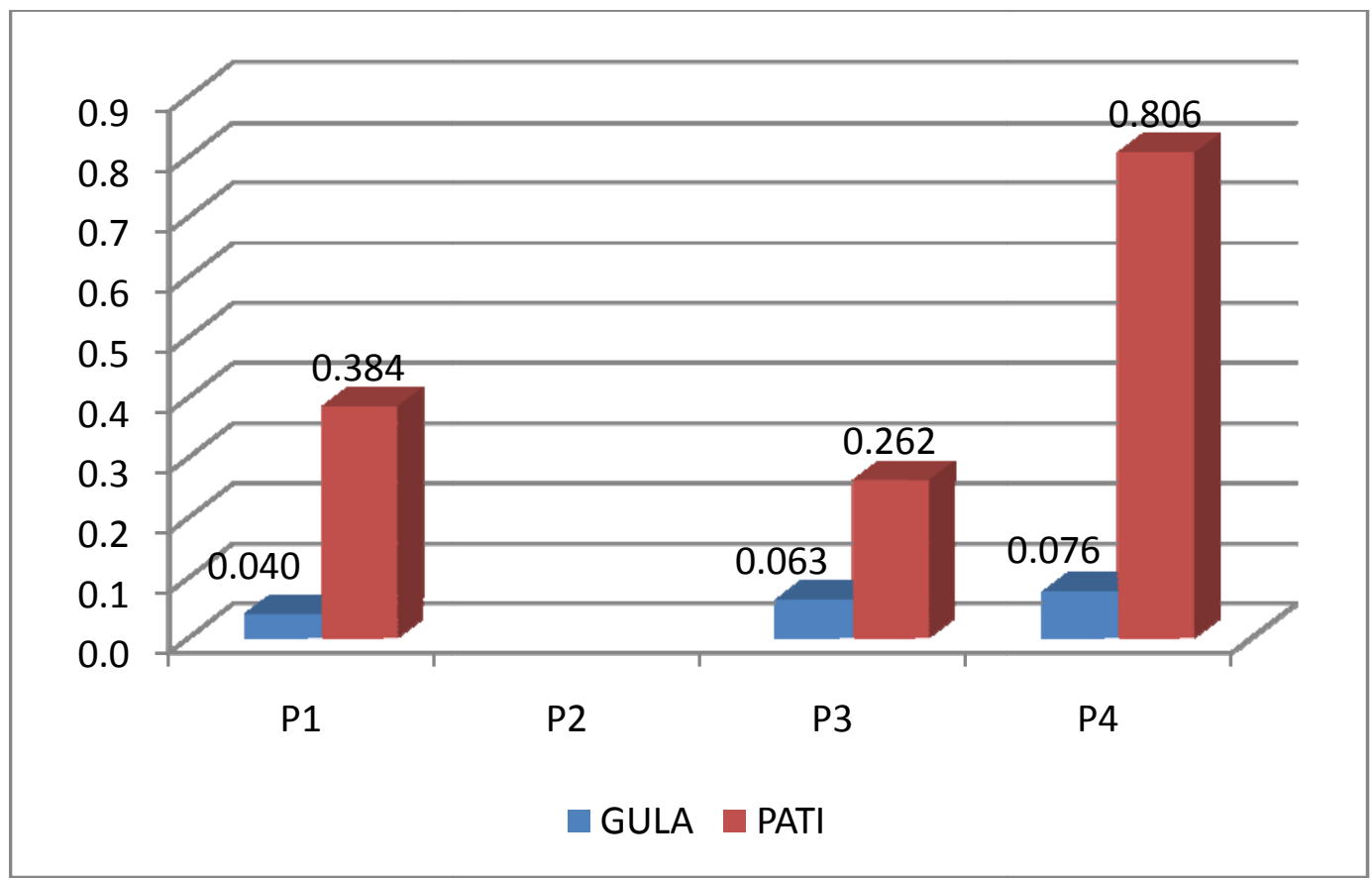

Gambar 4. Kadar Gula dan Pati Total. Perlakuan BAP 0 ppm (P1); 2,5 ppm (P2); 5 ppm (P3), dan 7,5 ppm (P4)

\section{Padatan Total Terlarut (PTT)}

Pelakuan BAP 7,5 ml/l mengandung padatan total terlarut yang paling tinggi
$(7,59)$ dalam residu media, diikuti pelakuan BAP $2,5 \mathrm{mg} / \mathrm{l}(7,13)$, kemudian pelakuan BAP $5 \mathrm{mg} / \mathrm{l}(6,77)$, dan pelakuan kontrol 
tanpa BAP mengandung padatan total terlarut terendah $(6,71)$ (Gambar 5). Padatan tatol terlarut yang tinggi dalam residu media dalam pelakuan BAP $7,5 \mathrm{mg} / \mathrm{l}$ mungkin karena konsentrasi BAP yang tinggi bisa menghalangi akar dari menyerap gula dari media. Namum, hal ini tidak selalu benar karena pelakuan dengan 2,5 mg/l mengandung lebih tinggi padatan total terlarut dalam residu media dari pada pelakuan BAP $5 \mathrm{mg} / \mathrm{l}$. Hal ini terjadi kemungkinan karena planlet yang dipersiapan untuk percobaan ini tidak homogen.

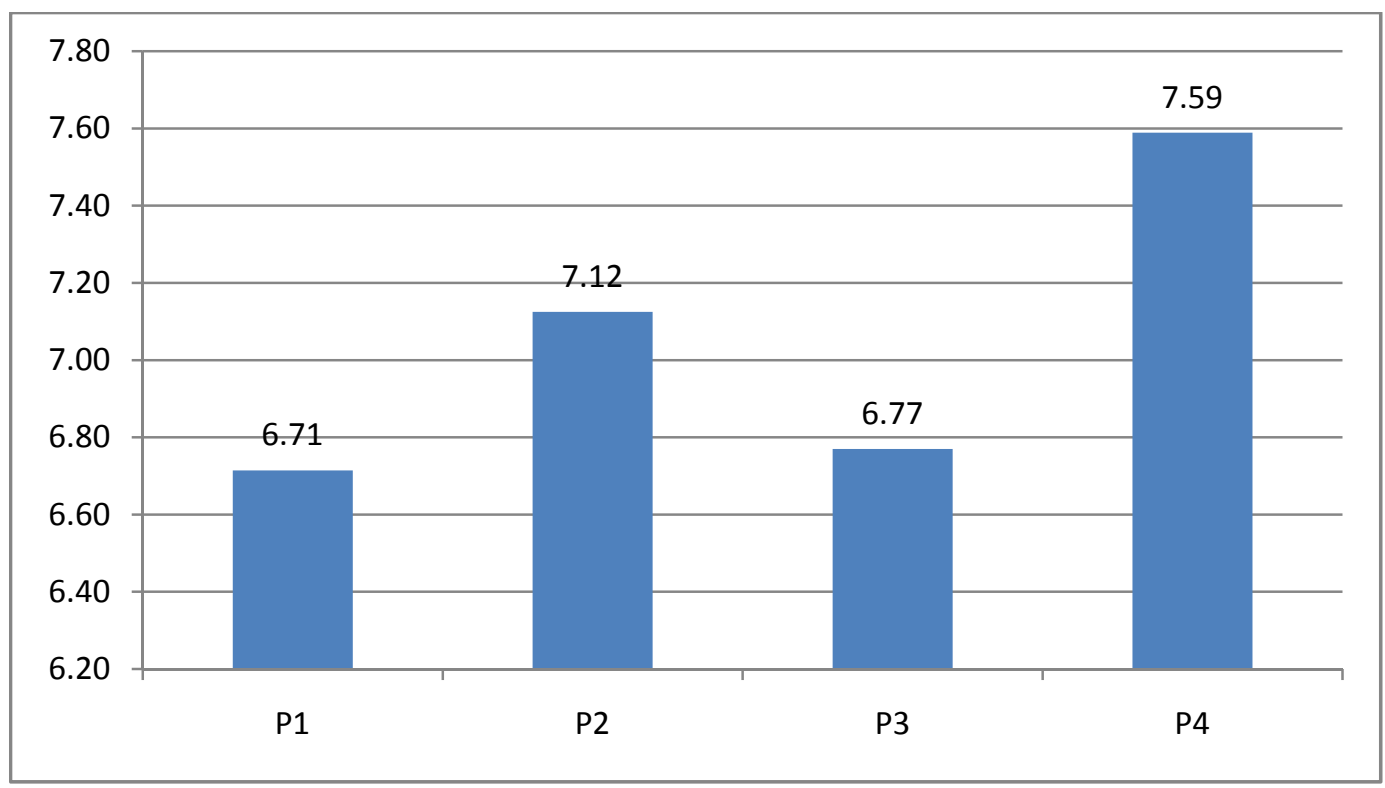

Gambar 5. Padatan total Terlarut (PTT). Perlakuan BAP 0 ppm (P1); 2,5 ppm (P2); 5 ppm (P3), dan 7,5 ppm (P4)

\section{KESIMPULAN}

BAP tidak memberikan pengaruh yang nyata terhadap jumlah umbi, diameter umbi, bobot basah dan bobot kering umbi. Umbi terbentuk paling cepat pada konsentrasi BAP 5 ppm. Jumlah, diameter, bobot basah dan bobot kering tertinggi pada konsentrasi BAP 5 ppm. Konsentrasi pati dan gula tertinggi pada konsentrasi BAP 7.5 ppm. PTT media sisa tertinggi pada konsentrasi BAP 7.5 ppm. Namun hasil yang diperoleh dalam percobaan ini belum dapat disimpulkan secara tegas pengaruh BAP terhadap terhadap pembentukan dan pembesaran umbi mikro kentang kultivar Granola karena performa planlet yang diamati pra-perlakuan telah berbeda.

\section{DAFTAR PUSTAKA}

Ashari, S. 1995. Hortikultura: Aspek Budidaya. Edisi Revisi. Penerbit Universitas Indonesia. P 139-140.
Avivi, S. dan Ikrarwati. 2004. Mikropropagasi Pisang Abaca (Musa textillis Nee) Melalui Teknik Kultur Jaringan. Jurnal Ilmu Pertanian, 11(2):27-34.

Belletti, P., S. Lanteri, S. Lotito, F. Saracco. 2009. Production of Potato MicroTubers through In Vitro Culture. ISHS Acta Horticulturae 362: International Symposium on Agrotechnics and Storage of Vegetable and Ornamental Seeds

Farid, M. 2003. Perbanyakan Tebu (Saccharum officinarum L. ) secara in Vitro pada Berbagai Konsentrasi IBA dan BAP. Jurnal Sains dan Teknologi. 3(3):103-109.

Garner, F. P., R. B. Pearce., R. L. Mitchel. 1991. Sitokinin : Fisiologi Tanaman Budidaya. Universitas Indonesia Pres.

Marina, S., J. Lumbangaol dan Irni. 2008. The Effect of Adding Benzil Amino Purine (BAP) and NApthalene Acetis 
Acid (NAA) to The Growth of Black Orchid (Coelogyne pandurata Lindl.) by Using In Vitro Technique. Prosiding Seminar Nasional Sains dan Teknologi-II. Universitas Lampung, 17-18.

Maryani, Y., dan Zamroni. 2005. Penggandaan Tunas Krisan Melalui Kultur Jaringan Jurnal Ilmu Pertanian. 12(1):51-55.

Moorby, J. \& F. L. Milthorpe, 1975. Potato. In: L. T. Evans (Ed.), Crop physiology. Some case histories, p. 225-257. Cambridge University Press, Cambridge.

Munin, L., Paiva, R., Ferreira, J.R., Alves, E., Nogueira., R., and Pereira, F.D.2008. Effect of cytokinins on in vitro development of autotrophism and acclimatization of Annona glabra L. In Vitro Cellular and Developmental Biology - Plant 44(2):128-135.

Rafique1, M., J. Jaskani, H. Raza and M. Abbas. 2004. In Vitro Studies on Microtuber Induction in Potato. International Journal of Agriculture \& Biology. Vol. 6(2). http://www.ijab.org. downloaded on $21^{\text {st }}$ May 2009.

Rostiana, O. 2007. Aplikasi Sitokinin Tipe Purin dan Urea pada MUltiplikasi Tunas Anis (Pimpinellla anisum L.)in vitro. Jurnal Littri, 13:1-7.

Sahat, S., Kusuma, and C. Enrique. 1998. Evaluation of 39 Potato Clones and Culture, In Java, Indonesia 1995 1998. Research Institute of Vegetables. Lembang. Bandung.

Salisbury, F.B. \& C.W. Ross. Fisiologi Tumbuhan. Jilid 3. Penerbit ITB Bandung. P.64-77.
Samadi, B. 2007. Kentang dan Analisis Usaha Tani. Yogyakarta: Kanisius. Hal.9-20.

Santi, V.M. 2004. Pengaruh Konsentrasi Paklobutrazol Dan Bap Terhadap Pembentukan Umbi Mikro Kentang Secara In Vitro. Fakultas Pertanian Universitas Sebelas Maret Surakarta.

Santoso, J. N. T. Mathius, U. Sastraprawira, G. Suryatmana dan D. Saodah. 2004. Perbanyakan Tanaman Kina (Cinchona ledgeriana Moens. dan C. succirubra Pavon) Melalui Penggandaan Tunas Aksiler. Menara Perkebunan, 72(1):1127.

Smith, O.E.\& C.E. Palmer.1970. Cytokinininduced tuber formation on stolons of solanum tuberosum. Physiologia $\mathrm{Pl}$. 23: 599-606.

Subatzky dan Yamaguchi. 1998. Sayuran Dunia1. Prinsip, produksi, dan Gizi. Penerbit ITB. Bandung. 313 hal.

Wattimena, G. A., 2000. Pengembangan propagul kentang bemutur dan kultivar kentang unggul dalam mendukung peningkatan produksi kentang di Indonesia. Orasi Ilmiah Guru besar Tetap Ilmu Hortikultura. Fakultas Pertanian. Institut Pertanian Bogor. 1992. Bioteknologi Tanaman. Departmen Pendidikan dan Kebudayaan. Direktorat Jenderal Pendidikan Tinggi. Pusat Antar Universitas Bioteknologi. Institut Pertanian Bogor. Bogor.145 hal.

Tanaman Kentang. Jurusan Budidaya Pertanian, Fakultas Pertanian Bogor. Bogor. $20 \mathrm{Hal}$. 